\title{
Presentación a los artículos de Mariana Mould de Pease y Franklin Pease G.Y.
}

La gentileza de Mariana Mould de Pease me lleva a escribir unas pocas líneas acerca de la relación de su artículo, que suceden a estas líneas, con el del Dr. Franklin Pease, mi maestro y amigo. Las reflexiones del Dr. Pease acerca del Cusco como centro del mundo en la obra de Garcilaso me recuerdan no solo sus clases y seminarios en la Pontificia Universidad Católica del Perú donde un grupo de estudiantes ávidos de aprender y conocer nuestra historia encontramos en el Dr. Pease al maestro y guía que intuyó nuestro interés y nos llevó a reflexionar sobre la Historia Andina a través, incluso, de seminarios fuera de clases. Fueron esos momentos los que marcaron mi pasión por la Historia y, sobre todo, por ese mundo mágico de la Historia Andina en la que él creía firmemente como la nueva manera de acercarse metodológicamente para lograr una cabal interpretación de esa realidad plasmada en las crónicas de los siglos XVI y XVII, como es el caso de la crónica del Inca Garcilaso de la Vega. La noción del Cusco como centro cósmico del mundo fue central para comprender ese mundo que se escondía tras la visión hispana que los cronistas no supieron entender ni transmitir, pero que, sin embargo, se escondía tras sus conceptos.

Mariana Mould de Pease recoge estos criterios para contrarrestarlos con la realidad del Cusco actual, en el que ese mundo mágico ha sido, no solo desacralizado, sino además destruido impunemente ante los ojos de las autoridades que han permitido la construcción de infraestructura turística a costa de los monumentos ancestrales que le valieron a esta ciudad el título de Patrimonio Cultural de la Humanidad por la UNESCO. Nadie duda de la necesidad de instalaciones modernas que alberguen el turismo, pero no es lo mismo destruir el patrimonio para poder lograr un objetivo lucrativo. Hoteles se pueden construir en muchas zonas sin necesidad de atentar contra el legado de nuestros antepasados.

A través de los artículos de Mariana Mould y de Franklin Pease se mide el contraste entre el análisis del pasado y la incuria del presente en la ciudad emblemática del Cusco, inspirador de los Comentarios reales de los incas y sede de la edificación que fue residencia del Inca Garcilaso de la Vega.

Pilar Remy Simatovic 


\title{
La restauración de la Casa Garcilaso en el Cusco, precedente a seguir cuando conmemoramos los 400 años del fallecimiento de este ilustre peruano
}

\author{
The Garcilaso House restoration in Cusco, it is the precedent to follow as we \\ commemorate 400 years of the death of this illustrious Peruvian
}

Mariana Mould de Pease ${ }^{1}$

\section{RESUMEN}

El Centro Histórico del Cusco desde tiempos prehispánicos hasta nuestros días ha pasado por innumerables trasformaciones, algunas con mucha violencia, desde que fuera descrito por su hijo más ilustre, el Inca Garcilaso de la Vega.

A partir de este testimonio hispano andino que data del siglo XVII, en este texto contextualizo dos casos representativos - el Hotel Marriott y el Hotel Sheraton- para destacar como el desbordado afán de lucro de las empresas constructoras y hoteleras en el siglo XXI atenta contra la autenticidad del Centro Histórico del Cusco. Este criterio aparentemente representativo de la economía de libre mercado se apoya en una legislación dada con carácter de urgencia para generar trabajo y cuya validez para el largo plazo debemos seguir estudiando ya que no toma en cuenta los convenios internacionales suscritos por el Perú en temas y asuntos de patrimonio cultural. Aquí sustento que aún son impredecibles los efectos que sobre nuestro patrimonio cultural tendrán estas medidas económicas de urgencia coyuntural, en el largo plazo de la vida peruana.

Consecuentemente, presento el contexto histórico en que la ética profesional de los arquitectos Víctor Pimentel y Emilio Harth-Terré, respectivamente, hizo posible hace más de cincuenta años preservar la autenticidad de la casa en que nació el mestizo más ilustre que tiene el Perú.

\section{Palabras clave}

Política cultural, conmemoración, testimonios; retrospectiva, contextualización.

\section{ABSTRACT}

Since pre-Hispanic era until today, the Historic Center of Cusco has gone through countless changes, some with great violence. Its most illustrious son, Inca Garcilaso de la Vega, has described it.

From this Andean Hispanic testimony dated from the seventeenth century, in this contextualized text exists two representative cases -the Marriott Hotel and the Sheraton-Hotel- to highlight how the profit motive of construction and hotel companies jeopardizes the authenticity of the Historic Center of Cusco.

This criterion, seemingly representative of the free-market economy is based on a legislation urgently given to create jobs, and that for reasons we must keep studying does not take into account the international agreements signed by Peru, on topics and subjects of cultural heritage.

\footnotetext{
1 Licenciada en historia por la PUCP y especialista en gestión, conservación y uso del patrimonio cultural. Es gestora de la "Colección Franklin Pease G.Y. para la historia andina del Perú" en la BNP. Ha sido Directora Asociada del Programa de la Universidades de Indiana y California, EEUU en el Perú y Vicepresidenta de ICOMOS. Es docente universitaria. Es investigadora, ha publicado numerosos artículos y ha recibido distinciones académicas.
} 
I support here that the effects over our cultural heritage will have these economic measures of relevant emergency in the long term of the Peruvian life.

Consequently, I present the historical context in which the personal and professional ethics of the architects Victor Pimentel and Emilio Harth-Terré, respectively, made possible over fifty years ago to preserve the authenticity of the house in which the most illustrious Peruvian mestizo was born.

\section{Keywords}

Cultural policy, commemoration, testimonies, retrospective, contextualization.

Este texto emana de la obra garcilacista de Franklin Pease G.Y. (1939-99) mi esposo; muy especialmente de su trabajo sobre el simbolismo de centro en la obra del ilustro cusqueño que se reedita en esta publicación.

\section{Veamos:}

El Cusco conserva la casa en que nació el Inca Garcilaso de la Vega (1539-1616) con las huellas dejadas en su estructura por las restauraciones efectuadas luego de los sismos de 1650 y 1950, entre otros ataques de la naturaleza y también alteraciones impuestas por las autoridades ediles, así como las modificaciones que debieron hacerle sus sucesivos poseedores desde 1539 para que se acomodaran a sus requerimientos. Ahora doy testimonio de lo ocurrido en 1964 para salvar la Casa Garcilaso gracias a que el arquitecto Víctor Pimentel, siendo un joven profesional, fue a Italia a capacitarse y perfeccionarse en restauración y así participara en la redacción y firma de la Carta de Venencia.

En palabras del arquitecto José Luis Beingolea:

Italia constituyó desde la pos guerra, el espacio práctico y reflexivo más desarrollado en la arquitectura contemporánea, prestando especial atención a la relación entre modernidad y tradición. En ese espacio, el desarrollo teórico y práctico de la arquitectura contemporánea, así como el pensamiento y la praxis en la restauración alcanzó uno de los puntos más altos de la época. (2015:11)

En 1965 estuvo en Varsovia, Polonia, para fundar el Consejo Internacional de
Monumentos y Sitios que actualmente tiene sedes en Lima nuestra capital política y en el Cusco, la capital histórica del Perú. En los años transcurridos desde entonces, el arquitecto Pimentel ha sido consecuente consigo mismo $y$ con los principios fundacionales de ICOMOS que fueron puestos a prueba a su regreso al Perú.

En los años en que el arquitecto Pimentel perfeccionaba sus estudios en preservación monumental en Italia, en nuestro país el Gobierno Militar, que el 18 de julio de 1962 había derrocado al presidente Manuel Prado (1889-1967), creó en agosto de ese año mediante un Decreto Supremo la Casa de la Cultura del Perú como una entidad con rango nacional formada partir de la Dirección de Educación Artística y Extensión Cultural establecida en 1941 dentro del Ministerio de Educación, durante la primera gestión del destituido mandatario. Ese régimen militar se debió a los rumores de fraude electoral y se propuso gobernar un año (1962 - 1963), tiempo que consideró necesario para convocar a nuevas elecciones presidenciales y congresales. En esa coyuntura política el Ministro de Educación fue el vicealmirante Franklin Pease Olivera (1905 -1976), mi suegro, quien dispuso la compra de la llamada "Casa de Pilatos", situada frente al Convento de San Francisco en el centro histórico de la capital del país para que fuera sede de esta naciente entidad cultural pública.

La restauración se hizo bajo la dirección del arquitecto Héctor Velarde (1898-1989). Mi padre Carlos Mould Távara (1910-1089), ingeniero civil, asumió en esta restauración el trabajo acorde con su especialidad. Este desenvolvimiento de política arquitectónica 
cultural fue retomado y continuado por el arquitecto Fernando Belaunde (1912-2012) cuando fue elegido presidente del Perú en 1963 (Lumbreras 2006). Hoy esa edificación colonial alberga al Tribunal Constitucional.

$\mathrm{El}$ arquitecto Belaunde miembro de una familia arequipeña de tradición demócrata se había educado en Francia y en Estados Unidos, países donde debió residir porque su padre, Rafael Belaunde Diez Canseco (1886-1972), había sido deportado por el gobierno autoritario del presidente Augusto B. Leguía (1863-1932). Cuando este arquitecto y político probo fue elegido presidente del Perú en 1963 incorporó a la política gubernamental peruana a algunos de sus antiguos alumnos y alumnas de arquitectura que por entonces eran unos prometedores jóvenes profesionales al nombrarlos en cargos públicos; sin embargo, el arquitecto Pimentel regresó a Lima y se mantuvo firme en sus convicciones de preservación del patrimonio urbano monumental del país despeñándose como arquitecto y funcionario en la Casa de la Cultura, sin aspiraciones de figuración política. Es en este contexto socio cultural que conocí al Arq. Pimentel, al lado del Dr. Franklin Pease G.Y. (1939-1999), mi esposo. En 1968 otro golpe militar depuso al presidente Belaunde e instauró el Gobierno Revolucionario de las Fuerzas Armadas (1968-1980) con el argumento que no había cumplido con los fines políticos para los cuales había sido elegido. Esos años fueron tiempos difíciles para quienes se desempeñaban en la Casa de la Cultura como arquitectos especializados en restauración de los monumentos coloniales $-\mathrm{O}$ virreinales, como hay quienes prefieren denominarlosporque el general Juan Velasco Alvarado (1910-1977) veía esta edificaciones como emblemas resultantes de la opresión española a la población andina durante tres siglos; para el Presidente del Gobierno Revolucionario de las Fuerzas Armadas había llegado el tiempo de poner autoritariamente las condiciones políticas para desaparecer las evidencias de Lima como ciudad virreinal, es así, que en el marco del Sesquicentenario se ensanchó el entonces denominado Jirón Cusco y se le puso el nombre de avenida Emancipación. El arquitecto Héctor Velarde (1898-1989), que se había educado en Europa por ser hijo de diplomático, fue también un escritor dotado de fino sentido de humor, desde $\mathrm{El}$ Comercio de Lima puso cuidadosamente - para evitar provocar las iras del general Velasco- su pluma al servicio de la defensa del patrimonio arquitectónico amenazado por el torcido entendimiento de la modernización urbana del espacio histórico que en ese momento apodó el "Damero de Pizarro". El Arq. Pimentel, como su colaborador sensible y valioso, debía enfrentar laboralmente estos avatares seudoconceptuales e ideológicos que hacen desaparecer nuestro patrimonio cultural en general y que lamentablemente son recurrentes. $^{2}$

La formación europea especializada del Arq. Pimentel, a su regreso al país, se proyectó sobre la preservación arquitectónica del Cusco cuando en 1964 debió exponer la visión debidamente sustentada, transparente, respetuosa, entre otros valores, así como desideologizada que respalda toda labor de identidad nacional. En esos tiempos de toma de decisiones democráticas individuales el Arq. Pimentel presentó públicamente una propuesta alternativa al proyecto del arquitecto Emilio Harth-Terré (1899-1983) que ya tenía la aprobación de la Municipalidad Provincial del Cusco para proceder a la demolición de esta emblemática edificación cusqueña y hacer una construcción neo hispánica en este lugar. Este señero arquitecto ante la contundencia de los argumentos técnicos y especializados de su joven colega tuvo la entereza ética personal de retirar su proyecto.

El arquitecto Harth-Terré había sido asesor de la Comisión Técnica de IV Centenario de la Fundación Española del Cusco en 1934, desde esta posición hizo la arquitectura del antiguo Hotel el Cuadro luego llamado de Turistas del Cusco (1938) en reemplazo de la edificación

\footnotetext{
2 Para una válida presentación de la obra de Víctor Pimentel Gurmendi y su trayectoria de vida profesional, véase la publicación que su discípulo el arquitecto José Luis Beingolea Del Carpio hizo en el 2015 de algunos de sus textos que estaban dispersos en impresos, y eran de difícil acceso.
} 
de la Casa de Moneda que ocupaba parte del espacio que en tiempos precolombinos se llamaba Cusipata, denominación que los españoles tradujeron como Plaza del Regocijo e instalaron a su vera el cabildo; como he conversado con el historiador cuzqueño Dr. Donato Amado quien es buen conocedor de este episodio alusivo a la transformación histórica urbana del Cusco que gravita sobre su desacralización. En el reparto de solares en los momentos iniciales del engendramiento del Perú le correspondió al capitán Sebastián Garcilaso de la Vega y Vargas (1507-59) una propiedad adyacente, dada por el derecho de conquista vigente en el siglo XVI y hoy proscrito por la legislación internacional; sin embargo, recordemos que así entró en el naciente Perú la noción de propiedad privada. El Inca Garcilaso, su hijo mestizo a quien bautizó como Gómez Suarez de Figueroa, inmortalizó esta edificación al narrar que desde su casa contemplaba las fiestas incaicas que todavía eran permitidas y las primeras fiestas españolas que allí se comenzaba a realizar. El Cusco en tiempos de la niñez de Garcilaso, —que tomó ese nombre hacia el final de sus días pasados en Montilla, pequeño pueblo andaluz próximo a Córdoba-, decía en 1916 don José de la Riva Agüero (1885-1944) con motivo del tercer centenario de su muerte en España:

El primitivo caserío de la ciudad había sido quemado por los soldados de Manco, quienes no respetaron sino cuatro palacios reales: Collcampata, Quishuarcancha, Amarucancha, con su alta torre delante. Los españoles comenzaban a derruir estos pocos edificios públicos salvados de los estragos del asedio, para labrar casas e iglesias en ello, o ensanchar las estrechas calles. Pero toda en el área restante quedaban, fácilmente indemnes del incendio $y$ los destrozos del cerco, largos y recios muros de sillería. Los conquistadores los aprovechaban para sus moradas, y decoraban la formidable severidad de aquella desnudez granítica de las ciegas paredes abriendo anchurosas puertas blasonadas y ventanajes de forjados hierros. (Riva Agüero 1944: XI.)
El Dr. Alberto Tauro del Pino (1914-94) bibliotecólogo y biógrafo del arquitecto HarthTerré, cuya ética profesional es -reiteroprecedente a seguir en estos momentos de construcciones hoteleras en el Cusco, ha dicho que él: "a través de su ejercicio profesional favoreció la adopción de un estilo neo-hispánico Ś...S y en la restauración de los monumentos coloniales buscó la autenticidad." (1987:937.)

La restauración de la Casa Garcilaso en el Cusco efectuada de 1964 a 1969 está esbozada de manera confusa en Internet (ARISTA-ARQMA. 2008); consecuentemente, es pertinente dar a conocer y contextualizar el testimonio del arquitecto Víctor Pimentel porque en estos tiempos el reordenamiento urbano del Cusco aparentemente se rige por los intereses de los inversionistas hoteleros apoyados en $-y$ respaldados por- los formalismos procesales del Poder Judicial del Perú. (Mould de Pease 2014.) Los medios de comunicación tanto limeños como cusqueños difunden desde el 2015 como todos los martes en la calle Mantas se reúne las y los cusqueños comprometidos con la autenticidad de su Centro Histórico para exponer por qué es irregular la construcción de un hotel "Four Points by Sheraton" de siete pisos en la calle Saphi del Centro Histórico del Cusco (Salcedo 2016). Las y los turistas extranjeros quieren saber el porqué de esta presencia ciudadana en el centro histórico más internacional de nuestro país.

Este es un proyecto de la empresa Inmobiliaria $R \& G$ S.A.C. que presentó unos planos para hacer una edificación de dos pisos acorde con los parámetros urbanísticos cusqueños como patrimonio cultural de la humanidad que fueron aprobados por la Municipalidad del Cusco y luego procedió a construir los referidos siete pisos con una arquitectura disonante con su entorno natural y cultural obviando el hecho fehaciente que en la calle Saphi todavía se conservaban andenes incaicos. Nadie desde la comuna edil o la sede cusqueña del Ministerio de Cultura tomó la decisión personal de detener esa obra ilegal. A mi entender, esta decisión personal está condicionada por la dación de la Ley 30230 en julio del 2014 que establece medidas tributarias, simplificación de procedimientos y permisos para la promoción 
y dinamización de la inversión en el país con la finalidad de promover el empleo. Esta ley en su artículo $\mathrm{N} .^{\circ} 60$ dispone la modificación de los numerales 22.1 y 22.2 del artículo N. ${ }^{\circ} 22$ de la Ley $N^{\circ}$ 28296, Ley General del Patrimonio Cultural de la Nación dando prioridad al trabajo inmediato y también a largo plazo por una supuesta y mal entendida finalidad turística. Esta ley amedrenta a las autoridades de los sectores de cultura gubernamentales porque las empresas constructoras y hoteleras la usan como instrumento legal para llevar a las personas ante un muy cuestionando Poder Judicial. (http://hereditas.pe/empresasse-beneficiarian-con-flexibilizacion-laboralen-contratacion-de-jovenes/ consultado 26 septiembre del 2016.)

Detrás de la razón social Inmobiliaria $R \& G$ S.A.C. se esconden arquitectos $-y$ quizás también arquitectas - así como otras y otros profesionales que desacralizan impunemente el Cusco, a mi entender, porque en lo personal no quieren comprender los efectos y consecuencias en el largo plazo de esta pérdida de identidad y su gravitación sobre el desenvolvimiento turístico, por un desbordado e inmediatista afán de lucro. Las y los miembros de ICOMOS Cusco ya informaron en francés, que conjuntamente con el inglés es idioma oficial de UNESCO, de manera interdisciplinaria sobre la cuestionable manera en que se lleva a cabo la construcción del hotel en la cusqueña calle Saphy. Este informe ha sido enviado a la sede internacional y parisina de ICOMOS por ser la vía en que UNESCO se informa de estos casos coyunturales y puntuales.

Este entendimiento se sustenta en mi testimonio en retrospectiva inmediata, por ello, aludo a que en el 2009 se inició la construcción del Hotel Marriott en la cusqueña calle de Santa Catalina Ancha sobre las ruinas del Convento de San Agustín que todavía conservaba andenes incaicos, el primer paso fue arrojar al río Huatanay y al amparo de la oscuridad piedras y otros vestigios tanto pre coloniales como posteriores a la conquista española de los Andes. Así puedo decir que a quienes nos atrevimos a protestar desde Lima vía los medios de comunicación nos amedrentaron con amenazadoras cartas notariales; al Dr. Oscar
Paredes Pando, profesor de la Universidad Nacional San Antonio Abad del Cusco que por entonces era regidor de la Municipalidad del Cusco y a la arqueóloga Edith Mercado, también profesora de la misma universidad les abrieron sendos procesos judiciales. A mi entender, se les siguió querellando a estas personalidades cusqueñas porque organizaron a la población cusqueña para hacer silenciosas vigilias nocturnas en la calle Santa Catalina Ancha donde ahora se yergue este hotel que forma parte de una prestigiosa cadena mundial. (Mould de Pease 2014.)

A pesar de este amedrentamiento empresarial por la vía judicial la protesta pacífica de la gente del común en el Cusco del 2009 en defensa de la autenticidad de su patrimonio cultural ha arraigado en su trama socio cultural, como vemos recurrentemente por los medios de comunicación. En retrospectiva básica de historia inmediata, ahora sustento que esta visible presencia cuzqueñista - para locales y foráneos- en defensa de la autenticidad de su entorno histórico urbano hizo que la historiadora Dra. Cecilia Bákula quien en esos momentos era Directora del Instituto Nacional de Cultura, creado por el Gobierno Revolucionario de las Fuerzas Armadas en 1971, a partir de la Casa de la Cultura considerada, que el Hotel Marriott del Cusco era una construcción neo-barroca. Cuando se inauguró el Hotel Marriott del Cusco con amplia cobertura mediática se publicó el libro que debe sustentar su arquitectura cuyos textos estuvieron a cargo de la Dra. Cecilia quién concluyó que:

Alcomprenderlaimportanciadel hallazgo de restos de estilo killke, Inversiones La Rioja optó por sacar a luz los sectores mejor conservados de la estructura lítica de este estilo tan regional y antiguo del Cusco. Estos fueron incorporados a la nueva propuesta arquitectónica, no solo porque constituían una manifestación de los cimientos fundamentales de la cuidad, sino porque probaban diversas teorías existentes. Y, ciertamente, porque confirman que los incas no se establecieron en un espacio deshabitado, ya que cuando eligieron asentarse en 
el Cusco en el siglo XII encontraron expresiones culturales precedentes, las cuales asimilaron $y$, sin duda, superaron en el tiempo. (Inversiones La Rioja S.A. 2012:33.)

Los editores de esta lujosa publicación bilingüe castellano-inglés, siguiendo un entendimiento autoritario empresarial ajeno al libre intercambio de ideas y conocimientos académicos que tan solo requiere citar las fuentes documentales, han puesto la siguiente nota editorial en este magníficamente ilustrado libro: "Este libro no podrá ser reproducido total o parcialmente sin la autorización escrita del editor". Evidentemente, no se puede reproducir en su totalidad ningún libro sin permiso escrito de sus primeros editores; pero, qué implica reproducir parcialmente sin ese permiso escrito ¿citar unas líneas del texto como lo hago aquí?, ¿están prohibiendo reproducir una de las hermosas fotografías de Beatrice Velarde?

Presentar estos testimonios en retrospectiva es pertinente a las celebraciones $y$ conmemoraciones con motivo de los 400 años de la muerte del Inca Garcilaso de la Vega para que nuestro país siga siendo coherente consigo mismo habida cuenta que el próximo año recordaremos el cuarto centenario de la publicación de la Historia General del Perú que este ilustre mestizo subtituló, Segunda parte de los comentarios reales de los incas.
Me explico:

En el Centro Cultural Inca Garcilaso del Ministerio de Relaciones Exteriores sito en el centro histórico capitalino y con amplia cobertura mediática limeña se presentó del 2 de abril al 8 de mayo del 2016 la exposición fotográfica "El Cusco de Garcilaso", en base al trabajo visual de Teo Allain Chambi, nieto del legendario fotógrafo Martín Chambi (18911973), a partir de los escenarios descritos tanto en los Comentarios Reales de los Incas (1609) como en la Historia General del Perú (1617). ${ }^{3}$

Viendo en el centro histórico de Lima esas 40 imágenes en blanco y negro captadas hacia 1989 en el Cusco, la capital histórica de nuestro país y expuestas por primera vez ese año en la capital política del Perú me he preguntado: ¿estamos haciendo lo posible y aún lo imposible por y para preservar la autenticidad del Cusco de Garcilaso?4

Para responderme a mí misma, rememoro que al lado de mi esposo Franklin Pease G.Y. conocí en 1965 al arquitecto Pimentel así más de cincuenta años después puedo dar testimonio que está dotado de fino trato personal para expresar sus puntos de vista aún en la discrepancia; también puedo decir que su proceder profesional es coherente con los principios y valores fundacionales del Consejo Internacional de Monumentos y Sitios que las y los miembros de ICOMOS

\footnotetext{
La capacidad de Martín Chambi para archivar sus fotografías y las de sus descendientes, para cuidar e incrementar este repositorio documental fotográfico es una expresión de identidad familiar que se proyecta sobre la identidad nacional. En esta tarea identitaria Julia Chambi López (1919-1973), fotógrafa por méritos propios, merece especial reconocimiento de nuestra parte por haber coadyuvado a su padre e inculcado a su sobrino Teo Allaín Chambi esta noción básica de preservación documental. En esta línea de razonamiento, debo decir aquí que la puesta en valor de los libros y otros documentos de mi esposo en la Biblioteca Nacional es llevada a cabo a través de la asociación público privada sin fines de lucro "Colección Franklin Pease G.Y. para la historia andina del Perú". (Mould de Pease 2016: 34-56.)

4 La bibliografía que refrenda este texto incluye citar publicaciones que llevan como corolario de las conmemoraciones por los cuatrocientos años de la muerte del Inca Garcilaso de la Vega el redactar unas consideraciones preservacionistas dirigidas a la comunidad de garcilasistas para que en el largo plazo de la historia se pueda contextualizar la desaparición de la edición La Florida del Inca impresa en Lisboa en 1605 de la Biblioteca Municipal del Cusco como informó el diario La República, y he consultado el 24 de septiembre del 2016 en: https:/www.facebook.com/pututuculturaollantaytambina/ posts/553508314764968

La vida y obra de este peruano fundacional conduce a promover en el siglo XXI la transparencia al citar las fuentes documentales sobre su ubicación y posesión para estudiar los documentos bibliográficos y manuscritos del Inca Garcilaso que han llegado a estos días. Esta tarea la llevo a cabo teniendo en cuenta las referencias documentales del Dr. Franklin Pease G.Y. (1939-99) en su libro Las crónicas y los Andes (1995).

La finalidad de esta tarea de recuperación documental es aportar a la investigación internacional interdisciplinaria para hacer viable la devolución de este ejemplar único a la ciudad natal de su autor porque los delitos contra el patrimonio cultural no prescriben en términos históricos y éticos.
} 
Cusco han traído al conflictivo presente cuzqueño. Esta asociación, sin fines de lucro, en el tiempo trascurrido ha ido agrupando a más de 10 mil miembros repartidos por todo el mundo que en estos años han elaborado un cuerpo de documentos fundamentales para la preservación del patrimonio cultural en general. El devenir de ICOMOS Perú en la década de 1990 cuando el Arq. Pimentel debió alejarse de su presidencia fue errático, quizás en parte por la manera autoritaria en que el Régimen Fuji-montesinista forzaba que fuera dirigido el Instituto Nacional de Cultura. El Arq. Pimentel desde principios del siglo XXI está comprometido con su buena marcha como su presidente honorario. Consecuentemente, la ocasión es propicia para recalcar que tanto en Lima como en el Cusco las y los miembros de ICOMOS siguiendo las enseñanzas del arquitecto Pimentel tenemos el compromiso ético de aportar a la defensa de la autenticidad de nuestra capital histórica promoviendo la preservación hispano andina de su espacio arqueológico, histórico, arquitectónico urbano en contra del desbordado afán de lucro hotelero incompatible con el hecho comprobado que las y los turistas vienen a experimentar el Cusco hispano andino que nació casi conjuntamente con Garcilaso (Eyewitness Travel 2009).

El sesgado e incongruente entendimiento de los negocios que tiene la Inmobiliaria R\&G S.A.C. es conducente a la desacralización del Cusco y su conversión en un parque de entretenimiento similar a Disneylandia de Miami y Los Ángeles; por ello, le pregunto al empresariado involucrado en el desenvolvimiento turístico de nuestro país para el largo plazo de la historia universal: ¿por qué no son capaces de seguir las pautas empresariales del Mundo de Disney en París que ha sido recreado a 32 kilómetros de la Ciudad de la Luz?

La propuesta gubernamental de "Peruanos por el Kambio" hace de este quinquenio un momento propicio para promover la reversión del tortuoso proceder empresarial hotelero cusqueño que se esconde detrás de la Inmobiliaria R\&G S.A.C., al amparo de un aún inexplicable cambio en la legislación vigente para que el Ministerio de Cultura se desligue de sus responsabilidades en nombre del Estado
Peruano por la protección del patrimonio cultural de la Nación Peruana, al entregar estas decisiones políticas a las municipalidades. Me refiero a la aludida Ley $\mathrm{N}^{\circ} 30230$ del 2014 cuyo artículo $\mathrm{N} .{ }^{\circ} 60$ modifica el artículo $\mathrm{N} .{ }^{\circ} 22$ de la Ley General del Patrimonio Cultural No 28296 para que no sea necesaria la autorización previa del Ministerio de Cultura al intervenir en todo bien cultural inmueble (prehispánico, colonial o republicano) como se puede ver en el blog del abogado Fabricio Valencia Gibaja (miembro de ICOMOS). Hago esta propuesta aun cuando el gobierno PPK en diciembre del 2016 ha dado como medida para la reactivación económica el DL No 1255 que modifica la Ley 28296 con la finalidad de contribuir a la contextualización histórica que debe preceder al debate para esclarecer el enfoque jurídico.

En Saphi hubo restos de andenería inca. En ese blog hay información sobre cómo en el Ministerio de Cultura de la India desde el 2010 tiene una propuesta legal que es sustentada esperanza para desentrampar la creciente demanda de la población urbana por lograr una forma de vida cómoda y articulada con la preservación de la autenticidad del patrimonio edificado arqueológico $y / 0$ histórico arquitectónico. Siguiendo estos pasos hindúes se trata de crear en nuestro país la Autoridad Nacional Monumental (ANM) que nos conduzca a una intercomunicación informativa veraz para lograr que ningún proyecto de construcción inmobiliario, minero y/o vial —sea gubernamental o privadoatente contra la autenticidad de los inmuebles arqueológicos y/o históricos. Ello incluye aplicar sanciones drásticas a quienes ya sea desde el sector público o del emprendimiento privado incumplan la Ley de monumentos históricos y sitios y restos arqueológicos. Este enunciado es mi traducción de: Ancient Monuments and Archaeological Sites and Remains (Amendment and Validation) Act (AMASR) 2010. (http://blog.pucp.edu.pe/blog/ aleajactaes/author/valencia-fa/ consultado el 24 de setiembre del 2016.)

Hago esta propuesta porque ya están internacionalmente trabajadaslas coincidencias y divergencias culturales inmateriales entre el Perú y la India, dado que también es un centro 
espiritual del mundo que atrae a millones de turistas (Eyewitness Travel 2009).

Estos testimonios sobre el Cusco se originan en el texto de Franklin sobre el Inca Garcilaso de 1969 cuya publicación adjunta ha sido posible gracias a Pilar Remy, alumna, discípula y amiga de mi esposo así como a Juan de Orellana, amigo, arquitecto y miembro de ICOMOS Perú. Este texto es un primigenio esfuerzo suyo por explicar que la religiosidad andina precolombina debe ser entendida a través del estudio de las fuentes escritas españolas cristianas, como integrada a las grandes religiones del mundo.

Concluyo citando unas últimas apreciaciones de Franklin sobre la obra del más ilustre de los cusqueños:
El Inca presentó siempre sus informaciones andinas como envueltas en un follaje verbal, acomodándolas al uso de sus tiempos en Europa; así, lo que suele confundir a sus lectores es la forma literaria que deleitosamente elabora, pues ella, "enmascara» la información histórica andina que elabora para presentarla a un público europeo. El contexto verosímil de Garcilaso -el de los cronistas- se encuentra en la forma como adapta su información a los criterios en boga en la Europa de sus tiempos para entender la historia; los datos verdaderos que desea presentar deben encuadrarse en este contexto. (Pease 1995:389; 2010:395)

\title{
Simbolismo de Centro en el Inca Garcilaso"
}

\author{
Center Symbolism in Inca Garcilaso
}

Franklin Pease G.Y.**

En la Historia de las Religiones tiene especial importancia la presencia del Centro religioso y su simbolismo. "Centro" es aquel lugar en que puede encontrarse una comunicación entre los tres mundos clásicos de los dioses, los hombres y los muertos, identificados con los planos celeste, terreno y subterráneo y cuyo punto céntrico es aquel el en que se da la más completa comunicación entre ellos.

Al estudiar la organización religiosa del país de los incas encontramos claramente tipificado el "Centro del Mundo" religioso, que en la época estatal es identificado con la ciudad del Cusco. Durante mucho tiempo se dijo, citando al Inca Garcilaso, que el Cusco era el ombligo del Imperio de los Incas, es decir, su centro, considerando este centro como una realidad geográfica como lo vieron los cronistas que afirmaron que en él se concentraba la red de caminos del Tahuantinsuyo. Cuando Garcilaso señaló esta identificación ${ }^{1}$ no quiso decir que era el Centro físico del Imperio -cosa negada por la geografía- sino que utilizaba la idea de que el "ombligo del mundo" era aquel lugar donde había comenzado la creación, según los Incas ${ }^{2}$. De esta manera se demuestra la existencia del símbolo del umbilicus mundi en pueblo andino. Ya hace tiempo Lehmann Nitsche escribió que el nombre del Cusco

* 1969 "Simbolismo de centro en el Inca Garcilaso". Mesa redonda de ciencias prehistóricas y antropológicas. Vol. II 49-52. Lima. Instituto Riva Agüero.

** Profesor principal y decano de la Facultad de Letras y Ciencias Humanas de la Pontificia Universidad Católica del Perú, profesor visitante en universidades de Estados Unidos, Japón, Inglaterra, Chile, Francia. Fue Profesor Honorario, miembro de diversas instituciones nacionales y mundiales, recibió diversas distinciones académicas y autor de artículos y libros sobre historia del Perú.

1 Garcilaso de la Vega, El Inca... Comentarios reales de los incas... En: Biblioteca de Autores Españoles, Vol. CXXXIII, Madrid, Ed. Atlas, 1960. Lib. I, Cap. XViii, p. 30.

2 Eliade, Mircea... Imágenes y símbolos... Madrid, Taurus, 1955, p. 46. 
no significaba "ombligo", sino aplanado artificialmente $(u \text { ordenado })^{3}$. Pero no se trata de otro significado, si se considera que la traducción de Lehmann Nitsche "arreglado artificialmente" puede asimilarse al centro ordenado por la divinidad o por encargo de ella. Y el Cusco es un centro religioso de acuerdo a la actual significación que tiene esta palabra, considerado como aquel “...punto ideal perteneciente no al espacio profano geométrico, sino al espacio sagrado en el cual puede realizarse la comunicación con el cielo o con el infierno"4. Así el Cusco estaba en el centro de los mundos que componían el cosmos del país de los incas ${ }^{5}$.

Entre los incas, como en muchos otros pueblos, se identificó el origen de su mundo con una montaña sagrada que era el centro del mundo creado, el lugar donde había comenzado la creación y que se suele colocar en un espacio sagrado, diferente, en el que es posible la relación con otros mundos ${ }^{6}$. Esta identificación con la montaña llama la atención en la presencia de la tierra como elemento a partir del cual se realiza la creación, como es posible comprobar en muchos mitos de creación andinos. "Del cerro Huanacauri salieron nuestros primeros reyes..."7, "La primera parada que en este valle hicieron... fue en el cerro llamado Huanacauri, al mediodía de esta ciudad, allí procuró hincar en tierra la barra de oro, la cual con mucha facilidad, se les hundió al primer golpe que dieron con ella..." La identificación de Huanacauri con la montaña sagrada sólo es evidente a través del Cusco vecino y vale la pena llamar la atención -además- sobre que el mismo cronista trae otras versiones del origen de los fundadores y siempre los hace salir de montañas 9 . Todos estos datos aunados a los aportados por otros cronistas, dan una idea de lo que simbolizaba la montaña para el sentimiento religioso del habitante del Tahuantinsuyo. Es notable que aún hoy día se identifique cierto tipo de creaciones con las montañas, tal como sucede en la comunidad de Puquio en que los wamanis son considerados padres tutelares que, además, aprovisionan a la comunidad de agua ${ }^{10}$. Otras versiones hablan de cerros divinos que fecundan mujeres cuyos hijos llevan el sello de su paternidad sagrada. Puede encontrarse una adoración a la montaña desde tiempos remotos y esto no es una novedad, desde que son ampliamente conocidas las ofrendas realizadas a los wamanis (aún en la actualidad) identificados con la montaña misma o con el espíritu que en ella se aloja, aunque hay que tener en cuenta que "la adoración no se tributa a las montañas en cuanto tales, sino a su poder", como escribe Van der Leeuw ${ }^{11}$; se adora el poder generador que tienen, al mismo tiempo que se reconoce el poder de unificar los tres planos del cosmos. Por otro lado, desde épocas primitivas pude encontrarse una identificación entre "Lugar sagrado", y "Cima de la montaña", pudiendo pensarse que si la huaca, lugar sagrado en los Andes está en la cima de la montaña, sirve de unión entre el mundo celeste o arquetípico y el terreno, desde que también hay que tomar en cuenta que el "cielo" más conocido se suele encontrar en los lugares más altos de las montañas ${ }^{12}$.

Lehmann Nitsche, Coricancha... Universidad Nacional de La Plata, Buenos Aires, Emp, “coni”, 1928, p. 22.

Eliade...Imágenes y Símbolos...p.83.

Garcilaso... op. cit... Lib. II, cap VII, p. 52.

Eliade... Imágenes y Simbolos... p. 45.

Garcilaso ... op. cit... Lib. I, cap. XVI, p. 27

Garcilaso... Loc. Cit.

Garcilaso... op.cit... Lib. I, cap. XVIII. P. 30.

10 Arguedas, José María... Puquio, Una cultura en proceso de cambio... Estudios sobre la Cultura actual del Perú... Prólogo de José María Arguedas ... Lima, Universidad Nacional Mayor de San Marcos... 1964. P.226. "Los peruanos creen que descienden de las montañas y de las piedras", ...es: entre Mircea Eliade (Eliade, Mircea... Tratado de Historia de las religiones... Madrid.) Instituto de Estudios Políticos, 1954, p. 237.

11 Van der Leeuw, Geradus... Fenomenología de la Religión... México, Fondo de Cultura Económica, 1964, p. 45. Podemos considerar la adoración del cerro bajo la forma de Wamani tradicional, como anterior a la conquista española, aunque las crónicas hablan muchas veces de la sola ubicación de huacas, en "cerros altos nevados", como sucede en la zona collagua (Relación de la provincia de los Collaguas... En Relaciones Geográficas de Indias, publicadas por $>$ Marcos Jiménez de la Espada. Madrid, 1885, t. II, p. 44) por ejemplo.

12 Van der Leeuw... op. cit. p. 45. 
La creación del mundo andino, es decir, el ordenamiento del caos por acción de la divinidad, se realiza por la pareja primordial Manco Cápac y Mama Ocllo, que aparecen en las crónicas, y en especial en Garcilaso, como los fundadores encargados de divulgar los principios esenciales de civilización.

El Inca Garcilaso trasmite en sus Comentarios reales los conceptos fundamentales de la tradición andina respecto del centro que era el Cusco, señalando que era el "ombligo del mundo", aunque como ya dijimos esta afirmación no puede tomarse en su sentido literal $^{13}$. El Cusco era la representación del Imperio, desde que era el lugar privilegiado de la creación ${ }^{14}$.

Es natural que encontremos en él una veneración excepcional, desde que para identificar el centro se requería una manifestación de la divinidad. Entre los incas $y$ en los Comentarios reales aparece esta cuando en la primera parada que en este valle hicieron... fue en el cerro llamado Huanacauri... Allí procuró hincar la barra de oro, la cual, con mucha facilidad, se hundió al primer golpe... Entonces dijo nuestro inca a su hermana y mujer: "En este valle manda nuestro padre el sol que paremos y hagamos nuestro asiento y morada, para cumplir su voluntad..."15. Así, se indica en la crónica la voluntad divina de señalar el centro entre los incas, y sabemos que en otros lugares del mundo la manifestación de la voluntad divina se realiza por medio del vuelo de las aves o por los gritos que éstas emitan, por ejemplo, y que son interpretados por los fundadores. La veneración que el Cusco despertaba hace que Garcilaso diga que "uno de los principalesídolos que los reyes incas y sus vasallos tuvieron fue la imperial ciudad del Cozco, que la adoraban los indios como una cosa sagrada, por haberla fundado el primer inca Manco Cápac..."16 lo que demuestra, por una parte, la veneración a la ciudad que se explica porque toda ciudad sagrada es una "montaña sagrada" 17 y por otra resalta la calidad arquetípica del primer inca legendario.

El poder de la divinidad otorgado a Manco Cápac es lo que lo convierte en arquetipo. En hombre antiguo no concibe ningún acto original, siempre lo remite a un antecesor; sus actos son siempre repeticiones y éstas son las que hacen la realidad ${ }^{18}$. La capacidad de ordenar el mundo, transformándolo de caos en cosmos se manifiesta a través de la fundación, es decir, de la incorporación de un territorio nuevo (hasta entonces perteneciente al caos) dentro del cosmos, a lo que debe seguir necesariamente la construcción de un Centro; esta construcción es, en cierto modo, una nueva creación del mundo ${ }^{19}$. Y así fundó Manco Cápac en Cusco ${ }^{20}$ y de la misma manera lo hicieron sus sucesores que "heredan" la misma capacidad de ordenar el mundo, realizándola en cada incorporación de territorio al Cusco.

Ya anotamos que una de las cualidades del fundador es divulgar los principios esenciales de la civilización, y así lo hacen los incas en el relato de Garcilaso ${ }^{21}$. La capacidad de fundación está relacionada con la sacralidad de la persona del inca, originada en el poder que esa persona tiene, es el poder lo que la hace divina ${ }^{22}$ y lo que hace que el inca como todo soberano esté resguardado por un tabú ${ }^{23}$. Es especialmente importante resaltar que el

13 Garcilaso... op. cit. Lib. I, cap. XVIII, p. 30.

14 Garcilaso... op. cit. Lib. VII, cap. IX, p. 258.

15 Garcilaso... op. cit. Lib. I, cap. XVI. p. 27.

16 Garcilaso... op. cit. Lib. III, cap. XX p. 112

17 Eliade, Mircea... El Mito del eterno retorno.... Buenos Aires, Emece Editores, 1959. p. 25.

18 Eliade... Mito del eterno retorno... pp. 18, 45.

19 Eliade... Imágenes y símbolos... pp. 51 - 55.

20 Garcilaso... op. cit. Lib. I, cap. XVIII, p. 30.

${ }_{21}$ Garcilaso... op. cit. Lib. I, cap, XV, pp. 226, 27, 39; Lib. III, cap. IV, p 92; Lib. III, cap. X, p. 97; Lib. III, cap. XII, p. 100; Lib. III, cap XV, p. 106; Lib. IV, cap XV, p. 136, y los ejemplos pueden multiplicarse.

22 Van der Leeuw... op. cit. p. 112, 210

${ }_{23}$ Eliade, Mircea... Tratado de historia de las religiones... Madrid, Instituto de Estudios Políticos, 1954. p. 29 Van der Leeuw... op. cit... p. 114 
inca configura un Centro movible, opuesto al centro estático que es el Cusco. Consideramos al inca como un centro religioso porque participa de los mundos celeste y terreno, desde que es considerado unido a la divinidad celeste y habitante del mundo terráqueo; su calidad de Hijo del Sol y al mismo tiempo su condición humana lo colocaban entre ambos mundos. Era considerado una divinidad por la masa, y así encontramos numerosos ejemplos en crónicas de la sacralización de un lugar por la presencia del inca. También son conocidos los casos de donación de ciertas especies que toman por ello características sacras. Sin embargo, vale la pena aclarar que esta calidad divina del inca parece inherente al cargo y no a la persona; lo divino es el cargo, no el hombre que lo ejerce. Solo así puede explicarse la suplantación de soberanos ocurrida varias veces en los últimos años del país de los incas, única época de la que podemos tener datos relativamente confiables acerca de los acontecimientos políticos. Si la persona que ejercía el cargo de inca fuera sagrada como el cargo mismo, habría sido imposible desplazarla del poder. La fundación se realiza, además, llevando algunos elementos de la ciudad-centro originaria, piedras por ejemplo. Cuando la fundación la realiza el mismo inca, podemos ver que la sacralización del lugar se produce por su contacto, como podemos ver repetidamente en las crónicas y, naturalmente, en los Comentarios reales ${ }^{24}$ ).

El considerar al inca como cargo sagrado no significó atribuir al mismo tiempo una cualidad divina a la élite, cosa que sucede en otros lugares ${ }^{25}$; sino que las crónicas, y en especial los Comentarios, marcan una diferencia tajante a este respecto; sin embargo, es necesario llamar la atención sobre que la élite no parece haber sido la mansa aristocracia que los cronistas, y Garcilaso señalan y que se puede verificar fácilmente la existencia de grupos antagónicos y aun opuestos al inca. A pesar de la reiterada afirmación de Garcilaso referente a la primacía absoluta del inca sobre la élite puede considerarse una situación a veces inversa.

Por otro lado, es necesario llamar la atención sobre la relación que existe entre las figuras de Manco Cápac y Pachacútec, tímidamente señalada por el cronista -además lo hace Murúa y Montesinos-. Ya se ha criticado la forma cómo trata Garcilaso a Pachatútec, a quien disminuye en beneficio de Huiracocha Inca, Amaru Yupanqui y Túpac Inca; sin embargo, destaca el hecho que señale como otro nombre de Pachacútec el de Titu Manco Cápac $^{26}$. Si analizamos esto, podemos entrever que la vinculación está referida a la calidad de arquetipo primordial que ostenta Manco Cápac y que ahora va a ser extendida a Pachacútec -"que renueva el mundo" según traducción del propio cronista-. Antes de la aparición del estado, y aun después, toda la vida incaica está referida a Manco Cápac, luego lo estará, además a Pachacútec. Las reformas (re-creaciones) del mundo, realizadas por este último, hacen pensar en si aparece aquí un nuevo arquetipo primordial que vuelve a ordenar el mundo, ahora mediante la creación de un estado centrado política y religiosamente en el Cusco, previamente reconstruido. Por último, cabe anotar que Garcilaso, influido por el cristianismo, asimila a los incas la cualidad de extirpadores de idolatrías, lo que es inaceptable ${ }^{27}$.

Finalmente tenemos que referirnos a la organización del templo como centro, calidad está extendida también a la ciudad y a la forma cómo la concibe el Inca Garcilaso de la Vega. El templo es también una montaña sagrada y por ello un centro ${ }^{28}$, y lo son también por extensión todos aquellos templos construidos a la manera original.

\footnotetext{
${ }^{24}$ Garcilaso... op. cit... Lib. III, cap. XIV, p. 102.

En los Comentarios pueden encontrarse múltiples casos en que se cita la sacralidad del inca, entre ellos: Lib. III, cap. VIII, p. 95; Lib. III, cap XIV, p, 102; Lib IV, cap, XXVIII, p. 188; Lib. VI, cap. XXXV, p. 240; Lib. VII, cap. VIII, p. 256; Lib. IX, cap. I, p. 333

25 Van de Leeuw... op. cit... pp. 112-113.

26 Garcilaso... op. cit.... Lib. IV, cap. XXVIII, p. 188.

27 Garcilaso... op. cit.... Lib. III, casp. XV y XVII, pp. 106 y 109.

28 Eliade... Mito del Eterno... p. 25.
} 
En todas las crónicas puede encontrarse una clara identificación del centro con el templo de Coricancha, que aparece comenzado a construir por el arquetipo primordial Manco Cápac y que fue, naturalmente, reformado por Pachacútec, que así aparecen vinculados estrechamente al templo primordial.

La repetición de las circunstancias que hicieron posible la aparición de un nuevo enviado divino y que hacen necesaria la re-creación realizada por Pachacútec hacen pensar en una regeneración cíclica del mundo incaico. Por otro lado, se advierte que en los Comentarios reales resalta especialmente la figura de Huayna Cápac con relación al templo del Coricancha, pues mientras todos los incas -relata el cronistaestaban mirando al pueblo, "Sólo Huayna Cápac se aventajaba de los demás, que estaba puesto delante del sol, vuelto a él como su hijo más querido y amado..." ${ }^{29}$. Sin embargo, es conveniente recordar que otros cronistas relatan una rebelión de la élite militar Cusqueña contra Huayna Cápac, y que toman como pretexto para el alzamiento la cólera de la divinidad solar motivada por el alejamiento prolongado del Inca Huayna Cápac de la ciudad del Cuzco.
Dentro del templo principal se aprecia (en una evidente actitud mestiza) que Garcilaso habla de un "altar mayor" (aunque el mismo cronista declare: "digámoslo así para darnos a entender") en el que se habría hallado una imagen solar de oro que en el reparto a los soldados españoles tocara a Mancio Sierra de Leguizamo ${ }^{30}$. Lo curioso aquí es que es la única representación solar de que se hace mención en crónicas (además de la que había en Tumibamba, según Murúa), lo que hace pensar en si la concepción que de la divinidad tenían los incas era tal que no permitía más que limitadas representaciones de ella, en oro por ejemplo, que es un metal solar.

En estos tres breves puntos hemos querido resumir los conceptos que sobre el centro religioso se encuentran en los Comentarios reales del Inca Garcilaso de la Vega. Consideramos que el concepto de centro religioso es fundamental para el análisis posterior de la estructura integral del Estado Inca, organizado en torno al Cuzco de acuerdo a los lineamientos del personaje mítico Manco Cápac que ordenara el mundo en nombre de la divinidad.

29 Garcilaso... op. cit. Lib. III, cap. XX, p. 113.

30 Garcilaso... op. cit. Lib. III, cap. XX, p. 113. 


\section{REFERENCIAS}

ARISTA-ARQMA (2008) Consultado el 23 de septiembre del 2016 en http://cuscoarquitectura. blogspot.pe/2008/08/informe-sobre-la-casa-garcilaso.html

Baez Fernando (2004) Historia universal de la destrucción de los libros. De las tablillas sumerias a la guerra de Irak. Buenos Aires. Editorial Sudamericana.

Baez Fernando (2008) El saqueo cultural de América Latina. México. Debate.

Baez Fernando (2013) Los primeros libros de la humanidad. El mundo antes de la imprenta y el libro electrónico. Madrid: Fórcola.

Bákula, Cecilia (2012) “Textos”. J. W. Marriott.Cusco. Páginas 15 -191. Editora: Beatrice Velarde. Lima. Inversiones La Rioja S.A.

Baker, Nicholson (2001) Double Fold. Libraries and the Assaut on Paper. Nueva York. Random House.

Beingolea Del Carpio, José Luis (2015) Víctor Pimentel Gurmendi y el patrimonio monumental. Textos escogidos. Lima. Universidad Nacional de Ingeniería.

EYEWITNESS TRAVEL (2009) Prólogo de Bill Bryson Off the tourist travel. 1000 unexpected travel alternatives. Londres \& Nueva York.

Durand Florez, José (1948) "La biblioteca del Inca" Nueva Revista de Filología Hispánica. II. 3. 239-264.

Durand Flores, José, Bruno Migliorini y Giulio Olchski (1949) "Sobre la Biblioteca del Inca". Nueva Revista de Filología Hispánica. IV, 2. 166-170. México.

De la Vega, Inca Garcilaso (1605) La Florida del Ynca. Historia del Adelantado Hernando de Soto, Governador e Indios; escrita por el Ynca Gacilasso de la Vega, capitán de su Magestad, natural de la gran cuidad del Cozco, cabeça de los Reynos y provincias del Perú. Dirigida al serenísimo Príncipe, Duque de Bragança. Con licencia de la santa Inquisición. Lisbona, Impresso por Pedro Crasbeeck. Con privilegio Real. Ediciones posteriores de 1617, 1723, 1829 uno de cuyos ejemplares podría haber sido el hurtado de la Biblioteca Municipal del Cusco. Ver también las siguientes ediciones: 2009a por Miguel Maticorena con el título: "Historia y Literatura. La Florida del Inca Garcilaso 1605". Tiempos revista de historia y cultura 4. Lima: UNMSM; 2009b con prólogo de Ricardo González Vigil, Lima. Universidad Inca Garcilaso; redición del trabajo aquí citado de Miguel Maticorena con prólogo de Eduardo Hopkins Rodríguez.

De la Vega, Inca Garcilaso (1722) Historia general del Perú... Segunda impresión, enmendada y añadida, con dos tablas, una de capítulos, y otra de materias. 2 vols. En la Oficina Real y a costa de Nicolás Rodríguez Franco, Impresor de Libros. Madrid.

De la Vega, Inca Garcilaso (1723) Primera parte de los comentarios ... Segunda impresión, enmendada: y capítulos, y otra, de las Cosas Notables, En la Oficina Real y a costa de Nicolás Rodríguez Franco, Impresos de Libros, Prólogo de Don Gabriel de Cárdenas, Madrid.

García, Gregorio (1607) Origen de los Indios del Nuevo Mundo. Estudio preliminar. Franklin Pease G.Y. [Segunda edición. 1729]. México. Biblioteca Americana. 1981

Flores Ochoa, Jorge (2012) "Releyendo al Inca Garcilaso". Revista Universitaria 1912 -2012. 141. 47-50. Cusco. Universidad Nacional del Cusco.

Hampe Martínez, Teodoro (1997) "José Durand, bibliófilo (su colección de libros y papeles en la Universidad de Notre Dame)". Revista de Indias. LVIII. 210. 541-562. Consejo Superior de Investigaciones Científicas. Madrid. 
ICOM 2016 http://icom.museum/programas/lucha-contra-el-trafico-ilicito/listas-rojas/L/1/ Consultado el 23 de septiembre del 2016.

López de Gómara, Francisco (1555) Historia General de las Indias. Zaragoza. 1993 Edición facsimilar a partir del ejemplar existente en la Biblioteca Nacional del Perú, a cargo de Franklin Pease G.Y Presentación de Aurelio Miró Quesada, con anotaciones del Inca Garcilaso y otras manos.

Lumbreras, Luis Guillermo (2006) "El papel del Estado en el campo de la cultura". Políticas Culturales. Ensayos críticos. Editores: Guillermo Cortés \& Víctor Vich. Páginas 71-112. Lima. Instituto de Estudios Peruanos. Instituto Nacional de Cultura. Organización de Estados Americanos.

Miró Quesada, Aurelio (1994) El Inca Garcilaso de la Vega. Lima. Fondo Editorial Pontificia Universidad Católica del Perú.

Mould de Pease, Mariana (2008) "Los bienes religiosos a nivel peruano e internacional". Revista Peruana de Historia Eclesiática.11. 237-262. Cusco. Academia Peruana de Historia Eclesiástica.

Mould de Pease, Mariana (2009a) "Remembranzas ante una ausencia garcilasista". Lundero. Publicación cultural de La Industria. Trujillo-Chiclayo. Mayo.

Mould de Pease, Mariana (2009b( "Al Obispado de Trujillo en sus 400 años, van algunas indagaciones sobre sus personajes y documentos". Lundero Publicación cultural de La Industria. Trujillo-Chiclayo. Julio.

Mould de Pease, Mariana (2013) "Unas reflexiones testimoniales ante la publicación de 'Los Incas en la Colonia. Estudios sobre los siglos XVI, XVII y XVIII". Tiempos 8 revista de historia y cultura. 43-84. Lima.

Mould de Pease, Mariana (2014) "Del Cusco incaico y barroco al Cusco turístico". Revista del Instituto Americano de Arte. 14. 49-61. Cusco. Instituto Americano de Arte.

Mould de Pease, Mariana (2016) "El «juicio de la historia» por el devenir de archivos, bibliotecas y otros repositorios documentales en el Perú del siglo XXI. Tinkuy 2. Páginas 34-56.Editores: Jorge Flores Ochoa, Martín H. Romero Pacheco. Dante Pozo Cevallos, Carlos Rado Yañez. Cusco. Centro de Estudios Andinos Cusco.CEAC.

Municipalidad Provincial del Cusco (2012) Proyecto. Mejoramiento integral, puesta al día y relanzamiento de la Biblioteca Municipal del Cusco. Reinventando la Biblioteca. Texto mecanografiado ajustado al 28 de diciembre. Autor: Romero Pacheco Martín.

Municipalidad Provincial del Cusco (2013) Gerencia de Turismo, Cultura, Educación y Deporte. Hacia la construcción de la política cultural estructural y de largo plazo de la Municipalidad del Cusco desde un plan estratégico. Desarrollando integralmente al ser humano cuzqueño desde la cultura. Texto mecanografiado al 2 de abril. Autor: Martín Romero Pacheco.

Paniótova, Taissia (2015) "La utopía como memoria: Retrospección de la obra del Inca Garcilaso de la Vega." América. Cruce de Miradas. II. 485-504. Coordinadora Teresa Cañedo-Argüelles. Madrid. Universidad de Alcalá. Asociación Española de Americanistas.

Pease G.Y., Franklin (1969) "Simbolismo de centro en el Inca Garcilaso". Mesa redonda Ciencias Pre-históricas y Antropológicas. I.205-211. Lima. Instituto Riva Agüero. Pontificia Universidad Católica del Perú.

Pease G.Y., Franklin (1976) Reseña a José Durand, El Inca Garcilaso clásico de América. México. SEPsetentas.

Pease G.Y., Franklin (1977) "Garcilaso a caballo" El Comercio. Lima 20 de mayo. 
Pease G.Y., Franklin (1977-80) Revista de la Universidad Católica. Nueva Serie. Lima.

Pease G.Y., Franklin (1979) Anuario de Letras.17.366-69. México.

Pease G.Y., Franklin (1983) "Garcilaso andino". Revista Histórica. XXXIV.41-52. Lima. Academia Nacional de la Historia.

Pease G.Y., Franklin (1985) Inca Garcilaso de la Vega. Comentarios Reales de los Incas. Prólogo de Aurelio Miró Quesada. Bibliografía Alberto Tauro del Pino. Edición al cuidado de César Pacheco Vélez. Lima. Banco de Crédito.

Pease G.Y., Franklin (1986) "El Inca Garcilaso de la Vega, un hombre de raíz andina en América y España”. Cultura. Córdoba. 24 de abril.

Pease G.Y., Franklin (1994) "Las lecturas del Inca Garcilaso y su información andina"”. Histórica. XVIII.1.135-57. Lima. Pontificia Universidad Católica del Perú.

Pease G.Y., Franklin (1998) "Garcilaso's Historical Approach to the Incas" Garcilaso de la Vega. An American Humanist. A tribute to José Durand. 32-42. José Anadón, editor.Notre Dame. Universidad de Notre Dame.

Pease G.Y., Franklin (1995) Las Crónicas y los Andes. Lima: Instituto Riva Agüero, Pontificia Universidad Católica del Perú, Fondo de Cultura Económica. 2010 Segunda edición al cuidado de Javier Flores Espinoza. Lima: Fondo de Cultura Económica.

Riva Agüero de la, José (1944) "Elogio del Inca Garcilaso". Historia General del Perú. (Segunda parte de los Comentarios Reales de los Incas). Edición de Ángel Rosemblat. 3 tomos. Páginas VII - XLIII.

Salcedo, José Víctor (2016) "Cusco: miles marcharon pidiendo la demolición del hotel Sheraton." Sociedad, página 22. Lima. La República. 21 de setiembre del 2016

San Martín, Juan (2015) "Raúl Porras Barrenechea, las crónicas y los cronistas. Entrevista a Carlos Aranibar Zerpa". Tiempos 10. Revista de historia y cultura. 55-69 Lima: Universidad Nacional Mayor de San Marcos.

Tauro del Pino, Alberto (1987). "Harth-Terré, Emilio", Enciclopedia Ilustrada del Perú, 3. 936937.Lima. PEISA.

Valencia, Gibaja, Fabricio (2010) Publicación virtual http://blog.pucp.edu.pe/blog/ aleajactaes/2010/11/11/nuevas-normas-hindues-referentes-a-la-proteccion-de-su-patrimoniocultural/ Consultada el 23 de septiembre del 2016.

Fecha de recepción: 29-09-16

Fecha de aceptación: 16-11-16 